\title{
AN EVALUATION OF FURCAL PERFORATION REPAIR USING MINERAL TRIOXIDE AGGREGATE AND RESIN MODIFIED GLASS IONOMER CEMENT WITH AND WITHOUT THE USE OF OPERATING MICROSCOPE- AN IN VITRO STUDY
}

\author{
Debjyoti Karmakar ${ }^{1}$
}

${ }^{1}$ Assistant Professor, Department of Dentistry, Murshidabad Medical College and Hospital, Murshidabad, West Bengal, India.

\begin{tabular}{l}
\hline ABSTRACT \\
\hline BACKGROUND \\
This study evaluated in vitro the effect of using the operating microscope on repairing furcation perforations using resin modified \\
glass ionomer cement or mineral trioxide aggregate.
\end{tabular}
glass ionomer cement or mineral trioxide aggregate.

\section{MATERIALS AND METHODS}

In this in-vitro study, forty-six extracted, human, permanent molar teeth with divergent roots and intact furcation area were used. They are sound or minimally restored. The teeth were divided randomly into four groups having 10 samples in each group. Using an ISO 012 round bur for furcal perforation were created in the teeth with in a slow-speed hand piece. Different materials were used in different group to repair perforation, with and without the use of the operating microscope. Two control groups- positive control and negative control, having 3 samples in each group were included in the study. In 100\% humidity, all groups of teeth were stored, and the repair materials were allowed to set and mature for $72 \mathrm{hrs}$. at room temperature and they were assessed for the quality of placement under X26 magnification. Using India ink for testing of leakage at the repair site, the teeth were then demineralized, dehydrated in alcohol, and made transparent in methyl salicylate. Then at X26 magnification dye penetration into the furcation repair was evaluated.

\section{RESULTS}

Perforations that were repaired with mineral trioxide aggregate significantly leaked less dye than resin modified glass ionomer cement $(\mathrm{p}<0.001)$. There was no significant difference in the quality of perforation repair with either material whether the operating microscope was used or not. Therefore, it can be inferred that quality of furcal repair can be better obtained with mineral trioxide aggregate when compared with resin modified glass ionomer cement. The use of operating microscope does not make any difference with the outcome of furcal perforation repair.

\section{CONCLUSION}

In this in vitro study, the furcal perforations repaired with mineral trioxide aggregate showed significantly leak-less dye penetration than those repaired with resin modified glass ionomer cement $(\mathrm{p}<0.001)$. Quality of furcal repair can be better obtained with MTA than RMGIC. The use of operating microscope (OM) makes no difference with the outcome of furcal repair.

\section{KEY WORDS}

Furcal Perforation, Mineral Trioxide Aggregate, Resin Modified Glass Ionomer Cement.

HOW TO CITE THIS ARTICLE: Karmakar D. An evaluation of furcal perforation repair using mineral trioxide aggregate and resin modified glass ionomer cement with and without the use of operating microscope- an in vitro study. J. Evolution Med. Dent. Sci. 2018;7(49):5241-5245, DOI: 10.14260/jemds/2018/1163

\section{BACKGROUND}

An endodontic perforation is "an artificial opening in the tooth or its root, created by the clinician during entry to the canal system or by a biological event such as pathological resorption or caries that result in a communication between the root canal and the periodontal tissue". ${ }^{1}$ (Jew R, Weine 1982).

A furcal perforation is a mid-curvature opening into the periodontal ligament space from sub-pulpal wall and is the worst possible outcome of any cleaning and shaping procedure. Its location is close to the clinical crown and

'Financial or Other Competing Interest': None.

Submission 11-09-2018, Peer Review 19-11-2018,

Acceptance 26-11-2018, Published 03-12-2018.

Corresponding Author:

Dr. Debjyoti Karmakar,

S/o. Satya Ranjan Karmakar

Durga Pally, P. O., Maliha, District,

Malda-732102, West Bengal, India.

E-mail:drdebjyoti@yahoo.com

DOI: $10.14260 /$ jemds $/ 2018 / 1163$ consequently is very likely to develop or continue microleakage from the coronal restorations into the space.

Iatrogenic damage in this region must be prevented in order to give a tooth a reasonable chance for long-term functional stability and freedom from endodontic infections. ${ }^{2}$

Except for resorptive defect or caries, root perforations are iatrogenic and are one of the main causes of endodontic failures.

The objective of endodontic perforation treatment are to seal the dentinal defect to gain regeneration of new periodontal attachment.

Perforation defect have been treated using a nonsurgical approach by intra-coronal placement of a repair material into the perforation. 3,4

Therefore, it is paramount importance that using a biocompatible material to completely seal the perforation.Many different restorative materials have been developed and used for non-surgical and surgical repair of iatrogenic perforation defects. Perforation defects have been sealed with different materials with varying degrees of success. These materials include zinc phosphate cement, ${ }^{5}$ glass ionomer cement, ${ }^{6}$ indium foil and amalgam, ${ }^{7,8}$ amalgam 
without surgery, ${ }^{9,10}$ cavit, gutta percha, ${ }^{8}$ calcium hydroxide, tricalcium phosphate, Teflon disk, dentine chips, zinc oxide eugenol, and hydroxyapatite. ${ }^{10}$

Super EBA was introduced in 1985 to restore endodontic perforation after first being used as a retrograde filling material.

Glass ionomer cement was introduced in 1990 to restore lateral root perforation. 2 Resin modified glass ionomer cement also perform better than the traditional GIC in perforation repair. In vitro repair of furcation perforation light cured glass ionomer cement exhibited a better seal than amalgam and cavit.

MTA (Mineral trioxide aggregate) possesses many of the ideal properties of a sealing material. Using both dye and bacterial leakage methods, in root end filling the, sealing ability of MTA has been seen to be superior to that of amalgam, intermediate restorative material, and super EBA and blood contamination it not adversely affected. ${ }^{11,12}$

In an in vitro study repairing lateral root perforations, methylene blue has been used to compare the sealing ability of MTA, to amalgam, and intermediate restorative material and MTA showed the least leakage and least over filling 12. In other study using an anaerobic bacterial leakage model, used to repair furcal perforations, MTA was significantly better and no leakage than amalgam. ${ }^{13}$

Pittford et al, 14 examined the histological response of MTA and amalgam, repair furcal perforations in dogs. Only one specimen of MTA showed inflammation and cementum deposition next to the surface of MTA was seen, whereas all the amalgam specimens demonstrated signs of inflammation,

The use of magnification has gained increased popularity in dental practice day by day. The operating microscope $(\mathrm{OM})$, provides an improved field of vision. This has provided a more conservative approach to perforation repair specially in case of internal repair and with the use of OM, avoiding the physical and psychological trauma of surgery to the operator. Clinical experience and a number of reports claim that using the OM provides better results. ${ }^{15,16-18}$

Incidence of perforation at furcation region of posterior teeth is not uncommon. Repairing this defect often poses difficulty because of vision within subpulpal wall and placement of a suitable material for repair. Operating microscope is of great help in this regard. Mineral trioxide aggregate andresin modified glass ionomer cement are often preferred as material for furcal repair.

Therefore, the present study was designed to evaluate furcal perforation repair using mineral trioxide aggregate and resin modified glass ionomer cement with or without the use of the operating microscope and to see the effectiveness of use of operating microscope in furcation repair.

\section{MATERIALS AND METHODS}

In this study forty-six extracted human permanent molar teeth with divergent roots and intact furcation area were used and they are sound or minimally restored. The teeth immersion in sodium hypochlorite for 30 mins for cleaning. With the help of periodontal curettes, soft tissue tags and calculus were removed. After washed thoroughly with normal saline and then teeth stored in normal saline.

The teeth were randomly divided into four experimental groups- Group 1, Group 2, Group 3 and Group 4, having 10 samples in each group and two control groups- positive control and negative control, having 3 samples in each group. A standard root canal access cavity was prepared in each tooth with diamond bur of access preparation set in and the content of the pulp chamber were removed, and the access cavities were irrigated with water. A block prepared by dental stone was used to set the tooth. A piece of cotton pellet dampened with water was placed of each tooth in the furcation area before they were mounted into the dental stone block using silicone impression material (Aquasil soft putty, Densply, York, PA).In the floor of the pulp chamber perforations were then made of each tooth excluding 3 teeth in negative control by using an ISO no. 012 round bur in a slow-speed handpiece. The width of perforation corresponded to the diameter of the bur, and the length of the perforation depended on the dentin and cementum thickness. The pulp chamber was filled with water for a few minutes. Remove excess moisture within the perforation help of Paper points before repair.

1. Group 1: In Group 1, 10 teeth with perforation were repaired using Resin Modified glass ionomer cement [RMGIC], (GC Asia Dental Pte Ltd-India) with the help of an operating microscope (Moeller Denta- 300) at 16x magnification. The material was mixed according to manufacturer's instructions (1 scoop of powder to 1 drop of liquid). With the help of the tip of an explorer a small amount of material was carried and allowed to flow into the perforation site. When the material apparently reached the apical end of the perforation, then material was light cured. For complete sealing of the peroration two incremental layers were applied.

2. Group 2: In Group 210 teeth with perforation were repaired using Mineral Trioxide Aggregate [MTA] (Pro root MTA, Dentsply Maillefer) with the help of operating microscope at 16x magnification. The MTA powder was mixed with water into putty consistency and was placed into the perforation site with a MTA carrier. Repair of each perforation a separate MTA mix was prepared. The material was packed in to the perforation site with a hand plugger and burnished. Using a cotton pellet dampened with water and placed in the furcation area..

3. Group 3: Ten teeth with perforation in Group 3 were repaired using RMGIC, as it was done in Group 1 samples, but under direct vision without the help of any magnification,

4. Group 4: Ten teeth with perforation in Group 4 were repaired using MTA, as it was done in Group 2 samples, but under direct vision without the help of any magnification.

Immediately after the repair, of each tooth a cotton pellet damped with water was placed in the pulp chamber and all the teeth were stored in humidity for $72 \mathrm{hr}$ at room temperature for allowed to set and mature of the repair material.

\section{Control Group}

Three teeth with furcal perforation consider as positive control where the furcal perforations were not repaired but the wall of pulp chamber was coated with two layers of nail polish. Another three teeth had an access cavity prepared but no perforation was done, and the wall of the pulp chamber 
were coated with two layers of nail polish consider as negative control group.

One operator assessed the quality of perforation repair by the microscope, who was unaware of the distribution of teeth among the groups. Each tooth was removed from its set putty, quality of perforation repair assessed at $8 \mathrm{x}$ and $24 \mathrm{X}$ magnification and repositioned in the set putty.

The repair was been filled within $0.5 \mathrm{~mm}$ of the furcal side or a slight overfilling considered as being clinically acceptable. Those samples were taken for study. If the repair did not extend to within $0.5 \mathrm{~mm}$ of the furcal side of the perforation or there was gross overfilling, consider as unacceptable repair. Those teeth were replaced by new one and procedure was repeated accordingly.

\section{Micro Leakage Assessment}

Use Indian Ink (Windros P \& Newton, London) for filling of pulp chamber of each tooth twice a day over a 5-day period. All the teeth were stored at room temperature and then washed thoroughly with tap water and dried. Group wise the teeth was then transferred in a separate glass vial and for demineralised use $11 \%$ nitric acid, until the texture was rubbery. A pin could be passed through the unimportant part of the root, this indicated that the demineralising process was complete. Then the teeth were washed thoroughly with water and remove all trace of acid before the procedure of dehydration was started. For dehydrated the teeth immersion in 70\%, 95\% and 100\% ethyl alcohol, successively for $24 \mathrm{hr}$ and finally transparent by storage in methyl salicylate.

Coronal dye penetration of the furcal repair teeth assessed by two operators blindly at $30 \mathrm{x}$ magnification. For the degree of dye penetration and teeth were scored according to following scoring system-

- $\quad$ Score 0 - No dye leakage could be detected.

- $\quad$ Score 1 -Dye leakage extending to $1 / 4$ of the repair material.

- $\quad$ Score 2 - Dye leakage extending to $1 / 2$ of the repair material.

- $\quad$ Score 3 - Dye leakage extending to $3 / 4$ of the repair material.

- $\quad$ Score 4 - Dye leakage beyond 3/4 of the repair material.

The collected data on micro leakage score were then subjected to Chi-Square test for statistical analysis.

\section{RESULTS}

In the positive controls dye penetrated the whole length of the perforation sites, whereas the negative controls showed no leakage (Figs. 1 and 2). In Table- 1 the results of leakage for the four experimented groups is shown.

\section{Statistical Analysis}

Showed that furcal perforations that were repaired with MTA significantly leaked less dye penetration than resin modified glass ionomer cement ( $p<0.001)$.Therefore it can be resolved that quality of furcal repair can be better obtained with MTA than RMGIC. The use of operating microscope (OM) makes no difference with the outcome of furcal repair.

\begin{tabular}{|c|c|c|c|c|c|c|}
\hline \multirow{2}{*}{ Group } & \multicolumn{5}{|c|}{ Leakage Score } & \multirow{2}{*}{ Total } \\
\cline { 2 - 7 } & $\mathbf{0}$ & $\mathbf{1}$ & $\mathbf{2}$ & $\mathbf{3}$ & $\mathbf{4}$ & \\
\hline Group 1 (RMGIC+OM) & 1 & - & 3 & 2 & 4 & 10 \\
\hline Group 2 (MTA+OM) & 8 & 2 & - & - & - & 10 \\
\hline Group 3 RMGIC & 1 & - & 4 & - & 5 & 10 \\
\hline Group 4 MTA & 8 & 2 & - & - & - & 10 \\
\hline Total & $\mathbf{1 8}$ & $\mathbf{4}$ & $\mathbf{7}$ & $\mathbf{2}$ & $\mathbf{9}$ & $\mathbf{4 0}$ \\
\hline Table 1. Frequency Distribution of the Leakage Score seen \\
in Experimental Groups
\end{tabular}

Assessments of Dye Penetration at $24 \mathrm{X}$ (Furcal Perforation Repaired with MTA at 16X)

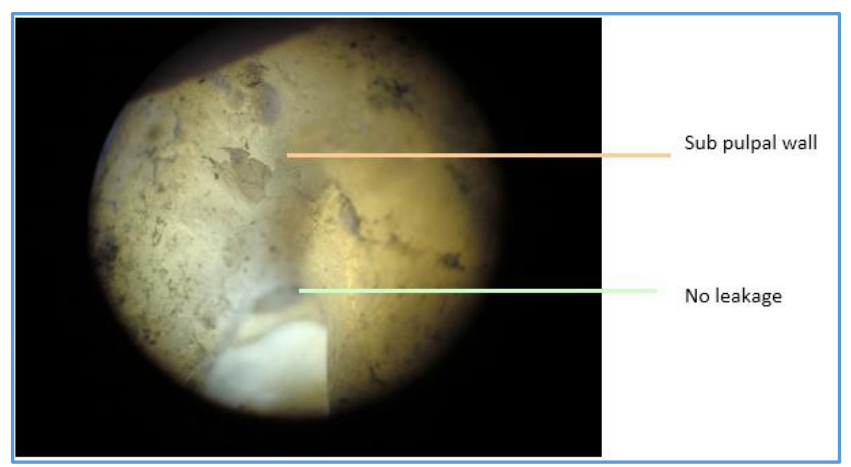

Figure 1. Score 0, No Leakage

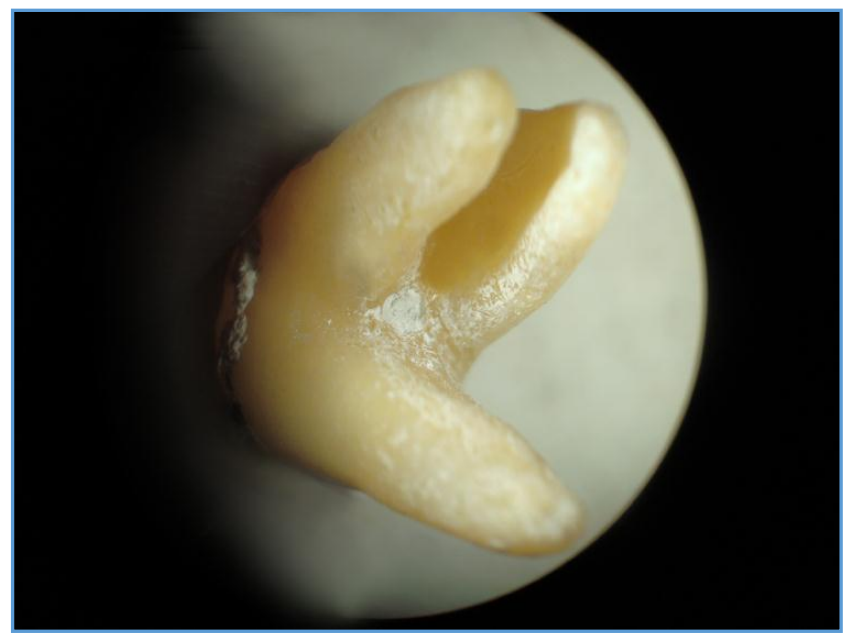

Figure 2. Acceptable Perforation Repair with MTA Viewed from Furcation at $8 \mathrm{x}$

\section{DISCUSSION}

Furcal perforation complicates endodontic treatment and compromises the prognosis if it is not managed properly. Once a perforation has been diagnosed, treatment must be rendered to seal the perforation site effectively to minimize the injury and contamination of the surrounding periodontal attachment apparatus.

Although many of these conditions are interrelated, location of the perforation and the time lapse between exposure and repair are the two most important factors determining success. ${ }^{19}$ 
It is crucial that the perforation site does not become infected and if possible, perforation site should be immediate repair. When choosing a suitable repair material, the sealing ability and the possible extrusion into the furcation area should be considered. Clinical experience and a number of reports have claimed that the management of these endodontic procedural errors using the $\mathrm{OM}$ have been very much help full and good visibility of the damaged site will help to facilitate the repair procedure. 16

In this vitro study, every possible effort to simulate the clinical conditions. The damp cotton pellet in the furcation areas did not act as a matrix for the repair procedure but simulated the clinical environment at the perforation site.

Coronal microleakage may be the result of failure of perforation repair 22. Therefore, in this study leakage was tested by a tracer dye, India ink. Under the condition of this study, MTA proved to be superior to RMGIC. Only 20\% teeth treated with MTA shows no signs of dye leakage. This confirms the finding of other studies regarding the sealing ability of MTA.

Lee SJ, Monsef M and Torabinejad M (1993), ${ }^{20}$ found that mineral trioxide aggregate had significantly less leakage than IRM or amalgam. The mineral trioxide aggregate also showed the least overfilling tendency while IRM showed the least under filling tendency.

According to Torabinejad M, Higa RK, McKendry DJ and Pitt Ford TR (1994), the amount of dye leakage with MTA was significantly less than that of amalgam, IRM, and super EBA. Presence or absence of blood had no significant effect on dye leakage.

Lee et al [1993], compared amalgam, IRM, and MTA in repairing experimentally created root perforations. The results showed that MTA had significantly less leakage than IRM and amalgam. MTA also showed the least overfilling tendency while IRM showed the least under filling tendency.

Thomas R.Pitt Ford et al (1995) ${ }^{21}$ mineral trioxide aggregate is a far more suitable material than amalgam for perforation repair, particularly when used immediately after perforation.

Nakata et al [1998], evaluated the ability of MTA and amalgam to repair furcal perforation in extracted human molars. Their findings showed that eight of the 18 amalgam samples leaked, whereas none of the 18 MTA samples did. MTA was significantly better than amalgam in preventing the leakage of $\mathrm{F}$. nucleatum past furcal perforation repair.

Abdel Rahman Hashem et al (2008) proved that Pro Root MTA has excellent sealing ability and can be used with or without matrix in repair of large furcation perforations.

The present study is an in vitro study and presence, or absence of blood is of no concern. So its effect on outcome of repair could not be evaluated. The parameter of tendency of over or under filling the perforation by the material used for repair was not considered in the present study. So, this very quality of MTA and RMGIC could not be compared in the present study.

In this study $90 \%$ of RMGIC specimens demonstrated signs of dye leakage. This may be the result of the damp conditions at the perforation site that may have interfered with bonding of the material to dentin. It has been reported that in dry conditions RMGIC can prevent bacterial leakage. 19

In vitro sealing ability studies comparing root end filling material have shown MTA to be superior to other commonly used materials. ${ }^{22-24}$ One explanation for this mechanism is the above-mentioned ability of MTA to spontaneously produce apatite in presence of phosphate-containing fluids which precipitates in the interface. ${ }^{25-29}$

MTA is the only material that demonstrates a biological compatibility and growth of a cementum like substance on the surface of the material that is either calcified or in its immature matrix form.

Above mentioned two properties of MTA make it a superior material for perforation repair compared to RMGIC, which do not possess these qualities.

According to H.N. Sempiraand Hartwell (2000) the operating microscope has many useful functions in endodontic therapy. The results of their study indicated that use of a surgical microscope did not increase the number of second mesiobuccal canals located, compared with those reports where access preparations were modified, and the microscope was not used.

The use of the OM was claimed that it provides better efficiency in locating root canals and their isthmuses, ${ }^{17}$ and increase in identification and treatment of $\mathrm{MB}_{2}$ in molar teeth reported by Stropko. 18

According to Louis J. Buhrley et al (2002),12 magnification of the operating field provided by the microscope and dental loupes is an important factor in successfully locating the MB2 canal.

However, these studies do not demonstrate the use of OM towards successful outcome of furcation repair.

Magnification loupes, head lamps and transilluminating devices along with operating microscope facilitate vision and are important adjunct in addressing perforations. They may be used to more predictably repair perforation defect nonsurgically, thus reducing the need for surgical intervention and its associated risks.

But, M. Firas Daoudi \& D William P. Saunders (2002),30 in their study evaluating the effect of using operating microscope on repairing furcal perforations with Vitrebond or mineral trioxide aggregate concluded that the use of the $\mathrm{OM}$ helpful in the repair procedure, but it had no effect on the quality of repair outcome. This result supports the observations of the present study.

\section{CONCLUSION}

So, within the limitations of this study, it can be concluded that furcal perforation repair with MTA resulted in significantly better leak-less dye penetration, compared with RMGIC. Also, the use of the OM helped in the repair procedure, but it had no effect on the repair outcome.

\section{REFERENCES}

[1] West J, Roane J, Goergia A. Cleaning and shaping the root canal system. In: Cohen S, Burns R, eds. Pathways of the pulp. $6^{\text {th }}$ edn. St. Louis Mosby: Year Book Inc., 1994.

[2] Gluskin AH, Peters CI, Wong RD, et al. Retreatment of non-healing endodontic therapy and Management of Mishaps. In: Ingle IJ, Bakland KL, Baumgartner CJ, eds. Ingle's endodontics 6. Lewiston, NY: BC Decker Inc., 2008: p. 1088-161.

[3] Torabinejad M, Watson TF, Pitt Ford TR. Sealing ability of a mineral trioxide aggregate when used as a root end filling material. J Endod 1993;19(12):591-5. 
[4] Asgary S, Parirokh M, Egbbal MJ, et al. Chemical difference between white and gray mineral trioxide aggregate. J Endod 2005;31(2):101-3.

[5] Lantz B, Persson PA. Periodontal tissue reactions after root perforation in dog's teeth: a histologic study. Odontol Tidskr 1967;75(3):209-37.

[6] Dazey S, Senia ES. An in vitro comparison of the sealing ability of materials placed in lateral root perforations. J Endod 1990;16(1):19-23.

[7] Auslander WP, Weinberg G. Anatomical repair of internal perforation with indium foil and silver amalgam: outline of a method. $N$ Y J Dent 1969;39(10):454-7.

[8] Aguirre R, elDeeb ME, elDeeb ME. Evaluation of the repair of mechanical furcation perforations using amalgam, gutta-percha, or indium foil. J Endod 1986;12(6):249-56.

[9] ElDeeb ME, ElDeeb ME, Tabibi A, et al. An evaluation of the use of amalgam, cavit and calcium hydroxide in the repair of furcation perforations. J Endod 1982;8(10):459-66.

[10] Balla R, LoMonaco CJ, Skribner J, et al. Histological study of furcations treated with tricalcium phosphate, hydroxylapatite, amalgam and life. J Endod 1991;17(5):234-8.

[11] Torabinejad M, Higa RK, Mckendry DJ, et al. Dye leakage of four root end filling materials: effects of blood contamination. Journal of Endodontics 1994;20(4):159-63.

[12] Torabinejad M, Rastegar AF, Kettering JD, et al. Bacterial leakage of mineral trioxide aggregate as a root end filling material. Journal of Endodontics 1995;21(3):109-12.

[13] Nakata TT, Bae KS, Baumgartner JC. Perforation repair comparing mineral trioxide aggregate, amalgam using an anaerobic bacterial leakage model. Journal of Endodontics 1998;24(3):184-6.

[14] Pitt Ford TR, Torabinejad M, Mckendary DJ, et al. The use of mineral trioxide aggregate for repair of furcal perforations. Oral Surg Oral Med Oral Pathol Oral Radiol Endod 1995;79(6):756-63.

[15] Daoudi MF. Microscopic management of endodontic procedural errors: perforation repair. Dent Update 2001;28(4):176-80.

[16] Wong R, Cho F. Microscopic management of procedural errors. Dent Clin North Am 1997;41(3):455-79.

[17] Yang SF, Hsu JR, Pai SF, et al. In-vitro efficacy of microscope and dye on identifying root canals in root end resection [Abstract]. J Endodon 1999;25:293.

[18] Stropko JJ. Canal morphology of maxillary molars: clinical observation of canal configuration. J Endod 1999;25(6):446-50.
[19] Jew RC, Weine FS, Keene JJ Jr, et al. A histological evaluation of periodontal tissue adjacent to root perforation filled with Cavit. Oral Surg Oral Med Oral Pathol 1982;54(1):124-35.

[20] Lee SJ, Monsef M, Torabinejad M. Sealing ability of a mineral trioxide aggregate for repair of lateral root perforations. Journal of Endodontics 1993;19(11):541-4.

[21] Torabinejad M, Smith PW, Kettering JD, et al. Comparative investigation of marginal adaptation of mineral trioxide aggregate and other commonly used root-end filling materials. J Endod 1995;21(6):295-9.

[22] Kettering JD, Torabinejad M. Investigation of mutagenicity of mineral trioxide aggregate and other commonly used root-end filling materials. J Endod 1995;21(11):537-42.

[23] Torabinejad M, Hong CU, Pitt Ford TR, et al. Tissue reaction to implanted super-EBA and mineral trioxide aggregate in the mandible of guinea pigs: a preliminary report. J Endod 1995;21(11):569-71.

[24] Torabinejad M, Hong CU, Pitt Ford TR, et al. Cytotoxicity of four root end filling materials. J Endod 1995;21(10):489-92.

[25] Tay FR, Pashley DH, Rueggeberg FA, et al. Calcium phosphate phase transformation produced by the interaction of the Portland cement component of white mineral trioxide aggregate with a phosphatecontaining fluid. Journal of Endodontics 2007;33(11):1347-51.

[26] Reyes-Carmona JF, Felippe MS, Felippe WT. Biomineralization ability and interaction of mineral trioxide aggregate and white Portland cement with dentin in a phosphate-containing fluid. Journal of Endodontics 2009;35(5):731-6.

[27] Sarkar NK, Caicedo R, Ritwik P, et al. Physicochemical basis of the biologic properties of mineral trioxide aggregate. Journal of Endodontics 2005;31(2):97-100.

[28] Bozeman TB, Lemon RR, Eleazer PD. Elemental analysis of crystal precipitate from gray and white MTA. Journal of Endodontics 2006;32(5):425-8.

[29] Taddei P, Tinti A, Gandolfi MG, et al. Vibrational study on the bioactivity of Portland cement based Materials for endodontic use. Journal of Molecular Structure 2009;924-926:548-54.

[30] Daoudi MF, Saunders WP. In vitro evaluation of furcal perforation repair using mineral trioxide aggregate or resin modified glass ionomer cement with or without the use of the operating microscope. J Endod 2002;28(7):512-5. 